\title{
Thermal Finite Element Analysis and Optimization of Carbon Steel Arc Stud Welding Parameters
}

\author{
Sabah Khammass Hussein \\ Welding Department, Engineering Technical College, Middle Technical University, Baghdad, Iraq \\ E-mail: sabah.kh1974@yahoo.com
}

\begin{abstract}
In this work an investigation to the temperature distribution during the stud arc welding process by building a thermal finite element (FE) model with the aid of Comsol- program was conducted. Also, an optimization to the ultimate applied torque of the welded stud and the total input heat during welding process by individual and composite desirability was intended. A stud of carbon steel- B7 is welded to a plate of carbon steel- grade- C. The welding machine parameters are; current, welding time and plunge. Three levels for each parameter, mentioned above, are used to optimize the resistance torque and the total heat flux using the design of experiments according to Taguchi method. The finite element model is built upon the input heat source, convection and radiation heat transfer during stud welding process. The tests include the torsional test and actual heat transfer depending on the record of temperatures at different locations. The suggested FE model gave good agreement with the experimental temperature record with an approximate error of $5 \%$. The results indicated that the torsional resistance increases with the increasing of weld time at small welding current of $400 \mathrm{~A}$. At higher welding current (I=800 A) the torsional resistance decreases with the increasing of the plunge welding value. The maximum temperature region lies at the center of the FE welded model and reduced gradually away from it with a symmetrical distribution. A sufficient welding heat input can make the torsional resistance of the weld line more than those of the stud. Due to the higher temperature gradient during the welding process, the microstructure of the welded joint exhibits three regions; nugget zone (NZ), thermo-mechanical affected zone (TMAZ) and the heat affected zone (HAZ). The first region consists of Martensite and ferrite phase with a higher plastic deformation, in which, the peak value of temperature was observed numerically. A coarse grain size with higher dislocations was found in the second stage. While, the HAZ gave a fine grain size without deformation due to mild thermal cycle is occurred in this region.
\end{abstract}

Keywords: Stud weld, FEM, welding heat input, Taguchi method.

ENGINEERING JOURNAL Volume 21 Issue 5

Received 9 February 2017

Accepted 22 April 2017

Published 29 September 2017

Online at http://www.engj.org/

DOI:10.4186/ej.2017.21.5.333 


\section{Introduction}

Stud welding is a joint method used in structural steel, boiler, shipbuilding and vehicle industries. Arc welding is the main principle of stud welding, in which, the heat is transferred between the stud and the plate. During the welding process, a change in the mechanical properties, microstructure and metallurgy occurred [1].

The drawn arc stud welding with ceramic ferrule is achieved through five steps [2] as shown in Fig. 1. Initially, the stud is brought in contact with the plate, after this and while the current is flowing, the stud is lifted off resulting in the creation of the arc. In the third step, the generated arc melts the surface of stud and plate. The stud eventually plunges in the weld pool and the joint is created.
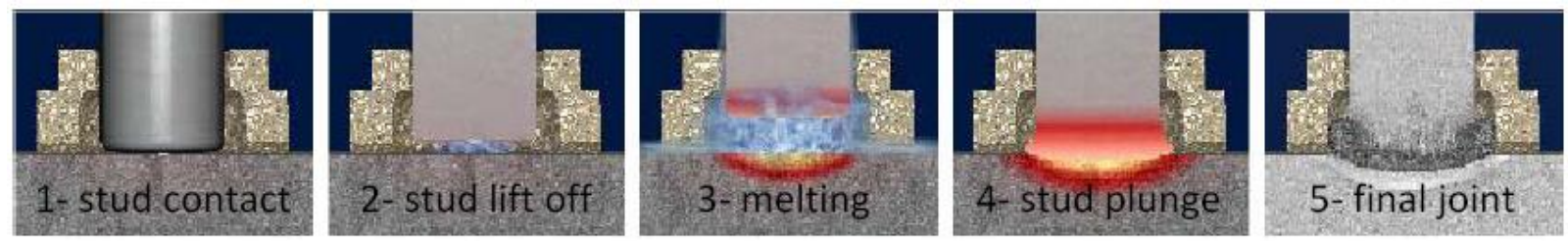

Fig. 1. Sequence of drawn arc stud welding with ceramic ferrule [2].

Two types of Boron steel with different thicknesses and coating layer were studied by drawn arc welding. The welding parameters were; the applied current, the lifting and welding time. The welded samples are tested by destructives bending test in order to determine the welding quality, depending on the steel type, coating and thickness. Welding of the uncoated Boron steel with low welding time gave good quality [3].

The temperature distribution during stud welding process was analyzed using FEM. The heat source was split into two parts; one directed towards the plate while the other is towards the stud. The higher thermal gradient gave stress transfer, residual stress and distortion. As well as, the nonlinear thermal treatment have an effect on the mechanical properties and microstructure [4].

The design of experiments method (DOE) is used in determining the parameters that affect the quality of the product. This method has been used by many researchers especially in improving the welding parameters which improve the mechanical properties of welds $[5,6]$.

The effect of stud welding process parameters (current, time, voltage, plunge, depth, etc.) and general manufactured variables (cleanliness, coating, joint design, etc.) on the welding quality were studied using design of experiment. The welding parameters depend on the size of the stud and material type. Incorrect base plate, inappropriate weld Settings, plate surface and lack of quality control cause the failure of stud welding material [7].

The analysis of the temperature distribution during welding process conducted by Comsol-program gave good agreement with the experimental data $[8,9]$.

In the present work, a FE model is proposed to analyze the temperature distribution in the friction stud welding. As well as, an optimization of the torsional resistance of the welded specimens and the heat input during welding process are performed using DOE.

\section{Finite Element Model (FEM)}

The finite element model was built using (COMSOL Multiphysics program-4.3) as shown in Fig. 2. The following steps included the definition of the equation's parameters, geometry, material properties, applied heat transfer and meshing the geometry. The analysis was of time dependent type.

The geometry of the model includes two parts; stud and plate. The stud model is built such that the lower surface contacts the upper surface of plate with the same centerline. The contact region is a representation of the weld pool. 


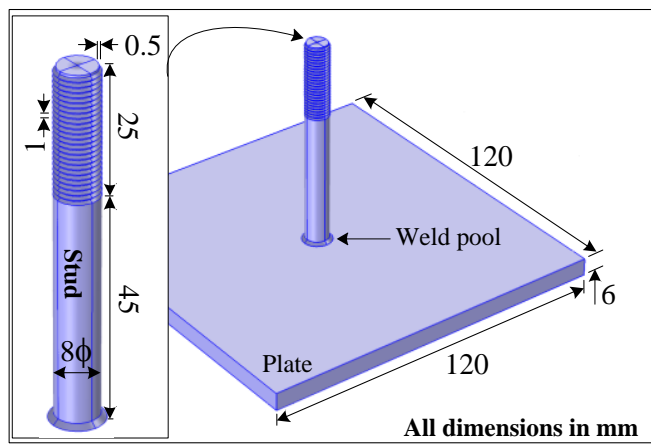

Fig. 2. Schematic diagram of the stud weld model.

Heat analysis in stud welding process consists of two parts; heat flux and heat loss from the surfaces of the stud and plate. A good heat flux approximation is derived depending on the double ellipsoid Gaussian distributed [10].

This approach is used to measure the heat flux near the weld pool and is given by:

$$
\begin{gathered}
q(x, y, z)=f \frac{6 \sqrt{3}}{a b c \pi^{3 / 2}} q e^{-3\left(\frac{x}{a}\right)^{2}} e^{-3\left(\frac{y}{b}\right)^{2}} e^{-3\left(\frac{z}{c}\right)^{2}} \\
q=\mu U I
\end{gathered}
$$

where:

$\mathrm{q}(\mathrm{x}, \mathrm{y}, \mathrm{z})$ : volumetric heat flux $(\mathrm{W} / \mathrm{m} 3)$ at any point (x,y and $\mathrm{z})$.

$\mathrm{f}$ : deposit power parameter in stud and plate, equal unity in this work [10].

q: power of source (W)

$\mu$ : welding machine efficiency.

$\mathrm{U}$ : voltage drop $(\mathrm{V})$

I : current $(\mathrm{A})$

a,b and c : radius of Gaussian double ellipsoid distributed heat.

The heat flux is applied at the circular contact surface between stud and plate as shown in Fig. 3:

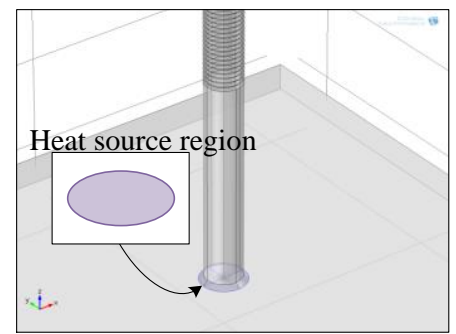

Fig. 3. Heat source region in stud welding.

The convection and radiation heat transfer lost, from the stud and plate surface, during welding process can be written as follows [11]:

$$
q=h\left(T_{O}-T\right)+\epsilon \sigma\left(T_{a m b}^{4}-T^{4}\right)
$$

where:

$q$ : heat loss from the stud and plate surface $\left(W / \mathrm{m}^{2}\right)$.

$\mathrm{h}$ : convection heat transfer coefficient $\left(\mathrm{W} / \mathrm{m}^{2} . \mathrm{K}\right)$.

$\mathrm{T}_{\mathrm{O}} \& \mathrm{~T}_{\mathrm{amb}}$ : initial and ambient temperature $(\mathrm{K})$.

$\varepsilon \quad$ : surface emissivity.

$\sigma \quad:$ Stefan-Boltzmann constant $\left(\mathrm{W} / \mathrm{m}^{2} \cdot \mathrm{K}^{4}\right)$. 
Equation (3) is used to calculate the heat loss from all surfaces of the stud and plate except the circular contact region which represents the heat source region. The meshed model is created as shown in Fig. 4.

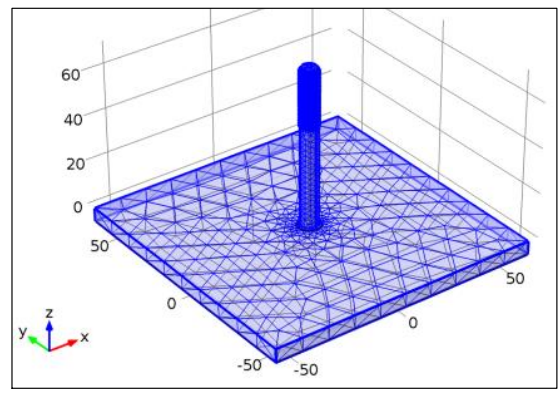

Fig. 4. Meshed model.

\section{Individual and Composite Desirability}

An optimal setting that maximizes the Torque and heat flux for stud welding is identified. To resolve this type of multi-output parameter design problems, an objective function of (x), can be defined as follows:

$$
\begin{gathered}
D F=\left(\prod_{\mathrm{i}=1}^{\mathrm{n}} \mathrm{d}_{\mathrm{i}}^{\mathrm{wi}} \frac{1}{\sum_{\mathrm{i}=1}^{\mathrm{n}} \mathrm{w}_{\mathrm{i}}}\right. \\
F(x)=-D F
\end{gathered}
$$

where:

$d_{i}^{w i}$ : the composite desirability defined for the (ith) targeted output $w_{i}$ : the weighting of the $\left(d_{i}^{m}\right)$

For various goals of each targeted output, the desirability (diwi) is defined in different forms [12]. The one-sided transformation:

$$
\operatorname{di}=\left\{\begin{array}{c}
0 \\
\left(\frac{\dot{y}_{i}-y_{i}^{(\min )}}{y_{i}^{(\max )}-y_{i}^{(\min )}}\right)^{r} \\
1
\end{array}\right\} \quad \text { if } \quad \begin{gathered}
\dot{y}_{i} y_{i}^{(\min )} \\
y_{i}^{(\min )} \leq \dot{y}_{i} \leq y_{i}^{(\max )} \\
y_{\dot{i}}^{(\max )} \leq \dot{y}_{i}
\end{gathered}
$$

The desirability rate of increase, (di), in the (ith) response depends on the variable (r). For three possible choices of $(r)$ the following statements are hold, when the desirability is constant, the relationship between (yi) and (di) is thought being linear. The value of (r) is taken as unity. If $\left(\dot{y}_{\mathrm{i}}\right)$, above the minimum acceptable values $\left(y_{i}^{(m i n)}\right)$ are of decreasing marginal worth, the relationship between (di) and $\left(\dot{y}_{i}\right)$ is concave and the value of $(r)$ is taken as less than unity. When the value of $\left(\dot{y}_{i}\right)$ above the minimum acceptable values $\left(\mathrm{y}_{\mathrm{i}}^{(\max )}\right)$ are of increasing marginal worth, the relationship between $\left(\dot{\mathrm{y}}_{\mathbf{i}}\right)$ and (di) is thought to be convex and the value of (r) is taken as greater than one [13].

The two-side transformations are:

$$
\begin{aligned}
& \mathrm{di}=\left\{\left(\frac{\dot{y}_{\mathrm{i}}-\mathrm{y}_{\mathrm{i}}^{(\min )}}{\mathrm{T}_{\mathrm{i}}-\mathrm{y}_{\mathrm{i}}^{(\min )}}\right)^{\mathrm{s}}\right\}, \text { if } \mathrm{y}_{\mathrm{i}}^{(\mathrm{min})} \leq \dot{\mathrm{y}}_{\mathrm{i}} \leq \mathrm{T}_{\mathrm{i}} \\
& \mathrm{di}=\left\{\left(\frac{\dot{y}_{\mathrm{i}}-\mathrm{y}_{\mathrm{i}}^{(\min )}}{\mathrm{T}_{\mathrm{i}}-\mathrm{y}_{\mathrm{i}}^{(\min )}}\right)^{\mathrm{t}}\right\}, \text { if } \mathrm{T}_{\mathrm{i}} \leq \dot{\mathrm{y}}_{\mathrm{i}} \leq \mathrm{y}_{\mathrm{i}}^{(\max )} \\
& 0
\end{aligned}
$$

As for $(\mathrm{r})$, the value of $(\mathrm{s})$ and $(\mathrm{t})$ can be taken to reflect constant, increasing or decreasing incremental worth of $\left(\dot{y}_{i}\right)$ as it approaches (Ti). The individual desirability (weighted desirability-(di)) is determined for 
all responses (torque and heat flux) depending on the type of quality characteristics. The selection of quality characteristic of two responses are taken as the larger-the-better [13].

\section{Experimental Work}

A carbon steel B7 stud of $8 \mathrm{~mm}$ diameter and $70 \mathrm{~mm}$ length of is to be welded with a square carbon steel plate (ASTM 283 grade C). The plate dimensions are $120 \mathrm{~mm}$ in length and $6 \mathrm{~mm}$ thickness. The mechanical properties for each material are listed in Table 1.

Table 1. Mechanical properties of stud and plate.

\begin{tabular}{c|cc}
\hline Material & Tensile strength MPa. & Yield stress MPa. \\
\hline carbon steel B7, ASTM 193 & 860 & 720 \\
ASTM 283 grade C & 400 & 200 \\
\hline
\end{tabular}

The direct current required for stud welding process is supplied by a power supply of type DABOTEK shown in Fig. 5. The range of direct current used is 200 to $1000 \mathrm{~A}$. The welding time range is $0.05-1 \mathrm{sec}$. with a time step of $0.05 \mathrm{sec}$. Drawn arc stud welding is used in this work, in which, the stud is ram into the gun chuck with a ceramic ferrule that is installed at the gun end. The chuck was placed perpendicularly on the plate. When the melting occurs, the stud then plunged into the plate.

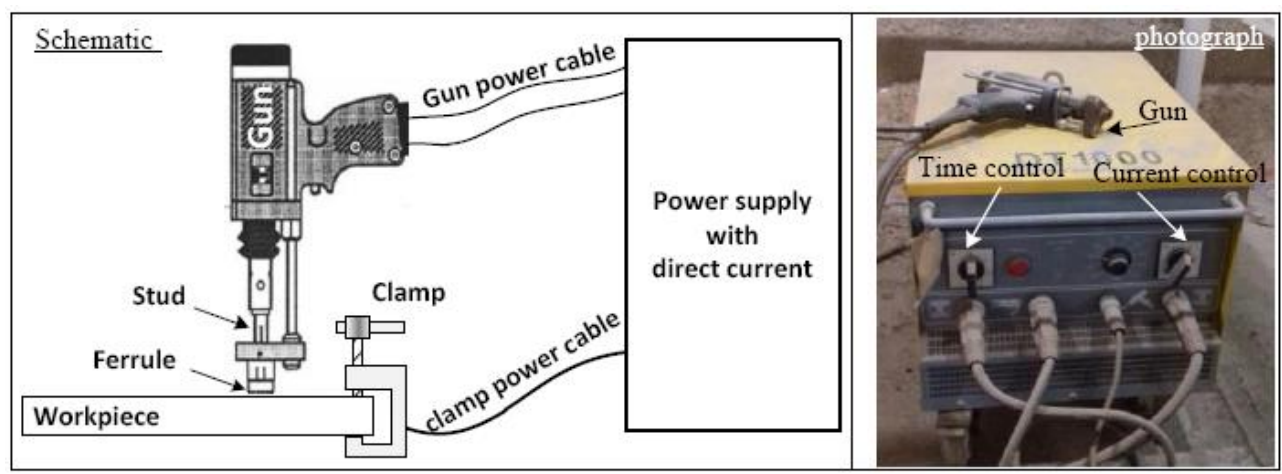

Fig. 5. Schematic of stud welding equipment.

Three stud weld equipment parameters are to be considered; plunge, welding current and time. Nine values for each parameter, mentioned above are tested, as shown Table 2 . The samples of the welded specimens are shown in Fig. 6.

Table 2. Experimental parameters.

\begin{tabular}{c|ccc|ccc|ccc}
\hline Test No. & 1 & 2 & 3 & 4 & 5 & 6 & 7 & 8 & 9 \\
\hline Current I, A & & 400 & & & 500 & & & 800 & \\
\hline Time t, sec. & 0.25 & 0.3 & 0.35 & 0.25 & 0.3 & 0.35 & 0.25 & 0.3 & 0.35 \\
Plunge P, mm & 2 & 4 & 5.5 & 4 & 5.5 & 2 & 5.5 & 2 & 4 \\
\hline
\end{tabular}




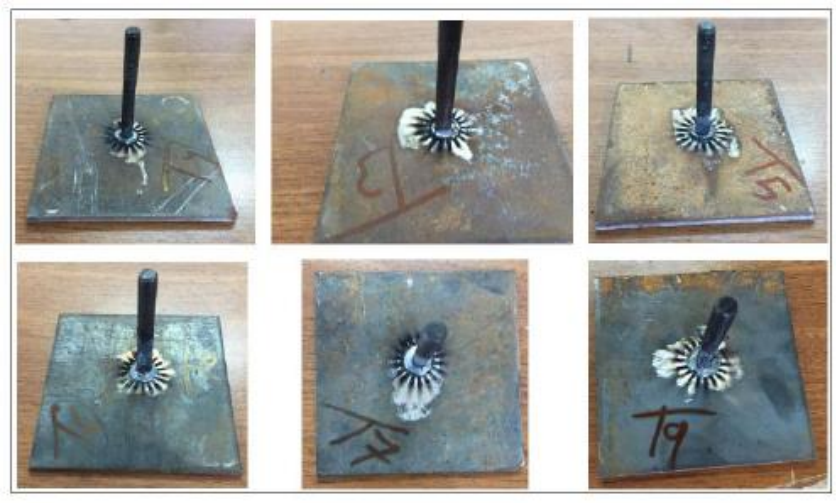

Fig. 6. Stud welding samples.

The performance and qualification of the welded stud was determined by twisting test. The torque is applied on the stud until failure is occurred. Figure 7 presents the method of applying torsional load to a welded stud.

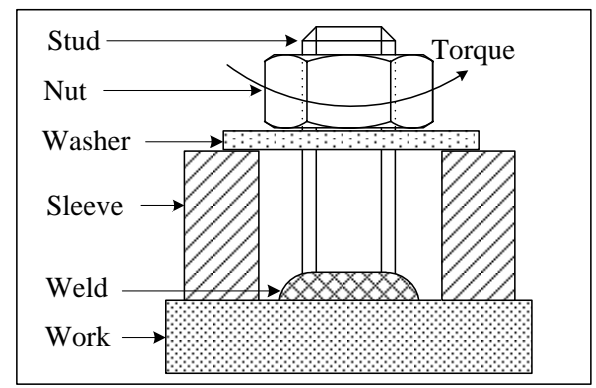

Fig. 7. Torque applied setup.

The verification to the FEM results was achieved by recording the temperature during the welding process using IR- thermometer device.

\section{Results and Discussion}

The effect of stud weld parameters: applied current, welding time and plunging on the stud torsion and temperature distribution are presented.

The specimens mentioned in Table 2 are tested by torsional test; the recoded values are shown in Fig. 8. The influence of applied current, welding time and plunging are clearly appearing. The minimum torque value is found in specimen 1 with minimum current of 400A. The maximum torque is found in specimen 6 with medium current of 500A. All specimens are fractured at the weld region except specimen 6, in which, the fracture is occurred at the stud region away from the weld line as shown in Fig. 9. In order to discuss the effect of torque, it must be taken into account that the stud welding process is principally an arc welding with the heat source generated by the electrode (stud). During welding process, thermal gradient variation with time resulted in phase transformation, internal cracks, voids and defects. The value of heat input depends on the applied current and welding time.

In specimens 1, 2 and 3, when 400A current was used, minimal torque values were observed as comparing to other specimens. Increasing the time and plunge at the same instance give a rise in torque value. When the time increases, the input welding heat increases. As a result, the fusion region is increased and good welding properties occur. Specimen 1 gave the minimum torque; hence, small applied heat produced incomplete fusion and discontinuous welding region with small voids, as shown in Fig. 9. The fractography of the specimen indicated that as the welding time increases, the region of homogeneous weld increases.

For the other set; specimens 4, 5 and 6, when 500A current was used, generally, the torque increased rapidly until the optimum value, specimen 6 . Discontinuous welding regions with incomplete welding are 
clearly observed in specimens 4 and 5 as shown in Fig. 9 who have small torsional values as compared to specimen 6 . The last specimen exhibits a continuous and homogenous surrounding weld line as shown in Fig. 9. It can be concluded that increasing the time for this current $(I=500 \mathrm{~A})$ give sufficient heat to produce the homogenous fusion with minimal voids and weld discontinuous.

The importance of the plunge appeared clearly in the final set of specimens 7, 8 and 9 when the applied current was $800 \mathrm{~A}$. Increasing the welding plunge with higher applied current reduces the mechanical property of weldment. Higher torque value was observed in specimen 8 in which a lower plunge value of $\mathrm{P}=2 \mathrm{~mm}$ was applied. A sensitive increase in torque is observed when the plunge increased from $\mathrm{P}=4$ to $5.5 \mathrm{~mm}$. It can be concluded that, plunge depth dominated welding properties more than welding time. Normally, higher applied current gave higher generated welding heat. Increasing the plunge depth means increasing the contact area and therefore, higher heat input is required to produce strong and homogenous welding. The welding heat input in specimen 8 , with small plunge depth $\mathrm{P}=2 \mathrm{~mm}$, small stud surface was sufficient to produce good mechanical welding properties. The homogenous continuous welding line was observed in this specimen, without incomplete fusion zone or voids as compared with the other specimens 7 and 9 as shown in Fig. 9.

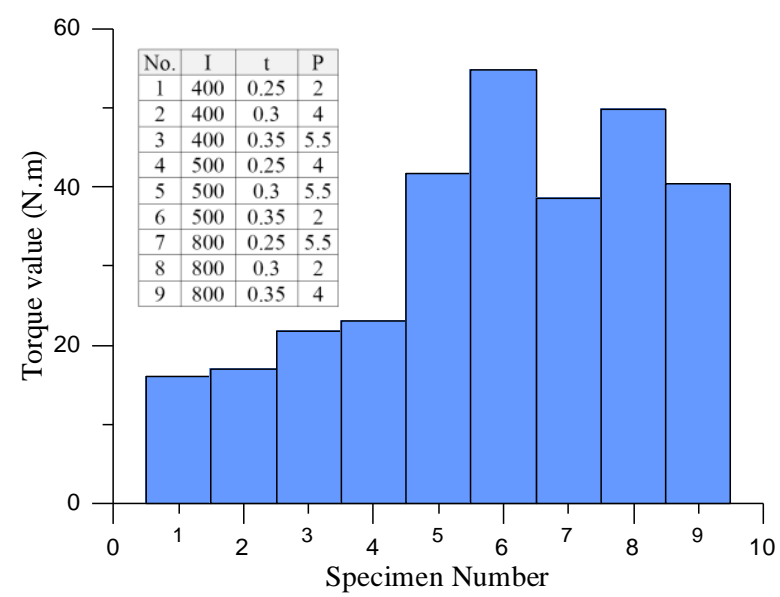

Fig. 8. Torque values of the tested specimen.
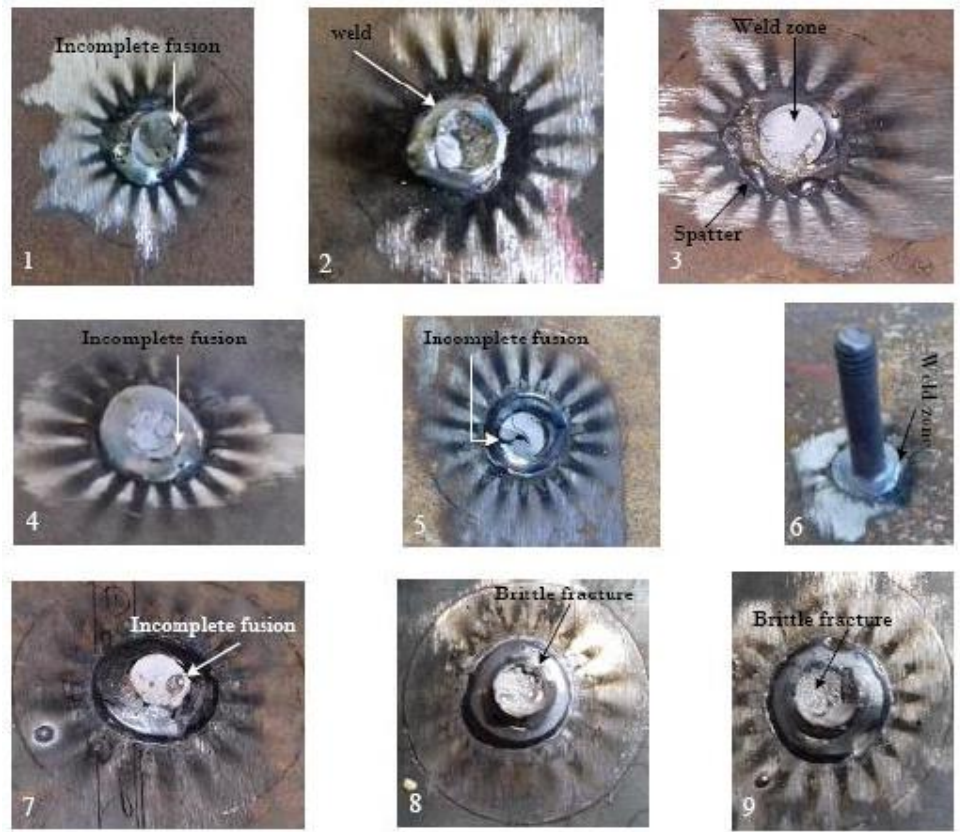

Fig. 9. The fractured specimens by torsional test. 
The temperature distribution the in stud and welded plate were calculated using the FEM model. Good agreement was observed in temperature recording between the experimental and FEM model as shown in Fig. 10. The percentage of the calculated error between the FEM and experimental recording was about $(5 \%)$.

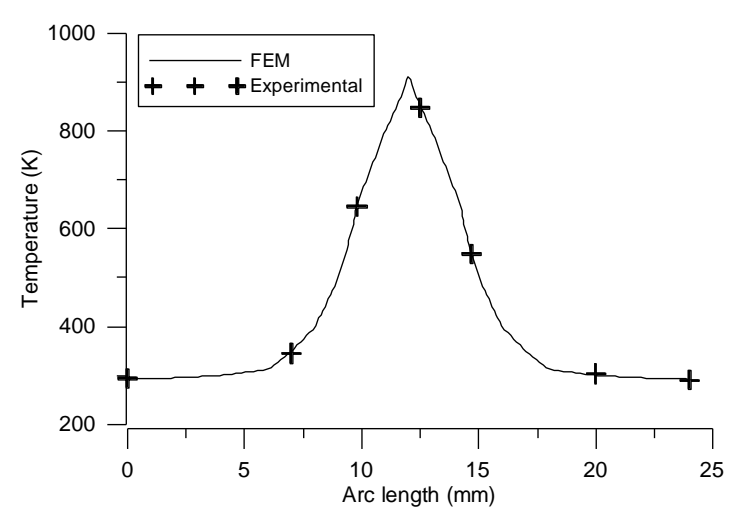

Fig. 10. Comparison the temperature between FEM and experimental, $\mathrm{I}=400 \mathrm{~A} ., \mathrm{t}=0.35 \mathrm{sec}$.

A sample of global temperature distribution was shown in Fig. 11 for specimen 8. The temperature starts from the ambient value at the regions away from the weld center. The maximum temperature of 1480 $\mathrm{K}$ was obtained at the center point, of the contact surfaces between the stud and plate. A uniform temperature distribution was observed throughout the center point of model.

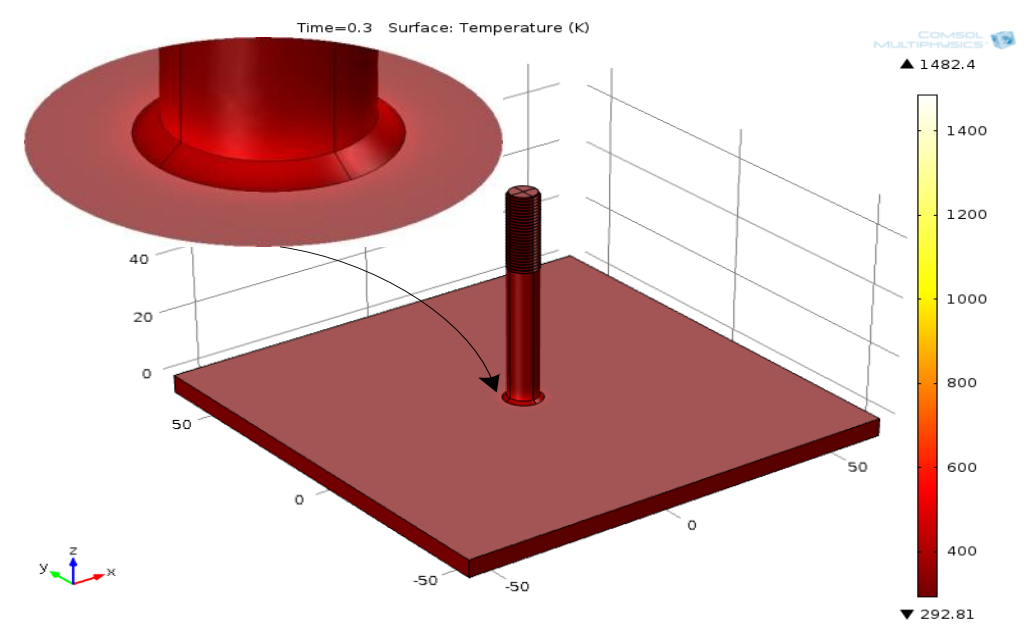

Fig. 11. Temperature distribution in specimen 8.

The temperature distribution of the suggested FE model can be presented along the model front and contact area sections. It can be seen from Fig. 12, a homogenous temperature distribution was observed throughout the model section. The maximum value of temperature was at the center point and decreases gradually away from this point.

Generally, the temperature distribution is symmetrical around the model center line. 


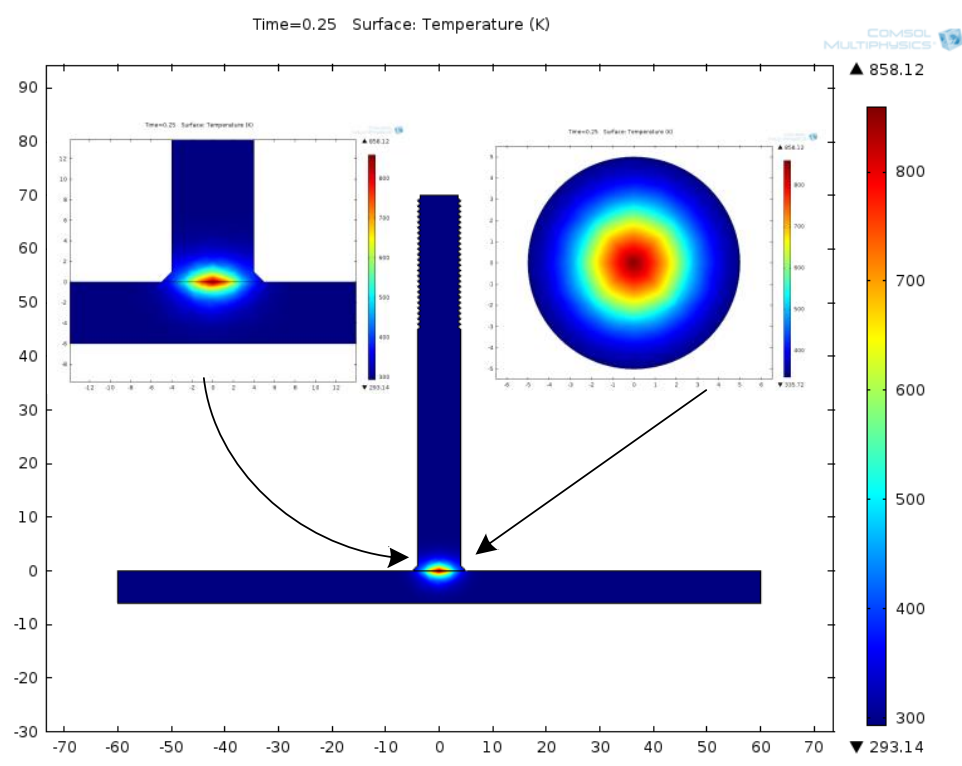

Fig. 12. Temperature distribution in model section of the first specimen.

The temperature distributions in the welded model were described for all specimens in Figs. 13-15. For each current, regardless of plunge, the temperature increases with the increasing welding time. Higher temperature ranges were found at the higher input heat (higher applied current). For each applied current, this higher range of temperature is confined at the stud section as compared to the welded plate. This can be consoled to the fact that the stud behaves as an electrode or heat input source. Away from the source of heat, the temperature decreased due to the heat lost by convection, conduction and radiation from large surface area of plate.

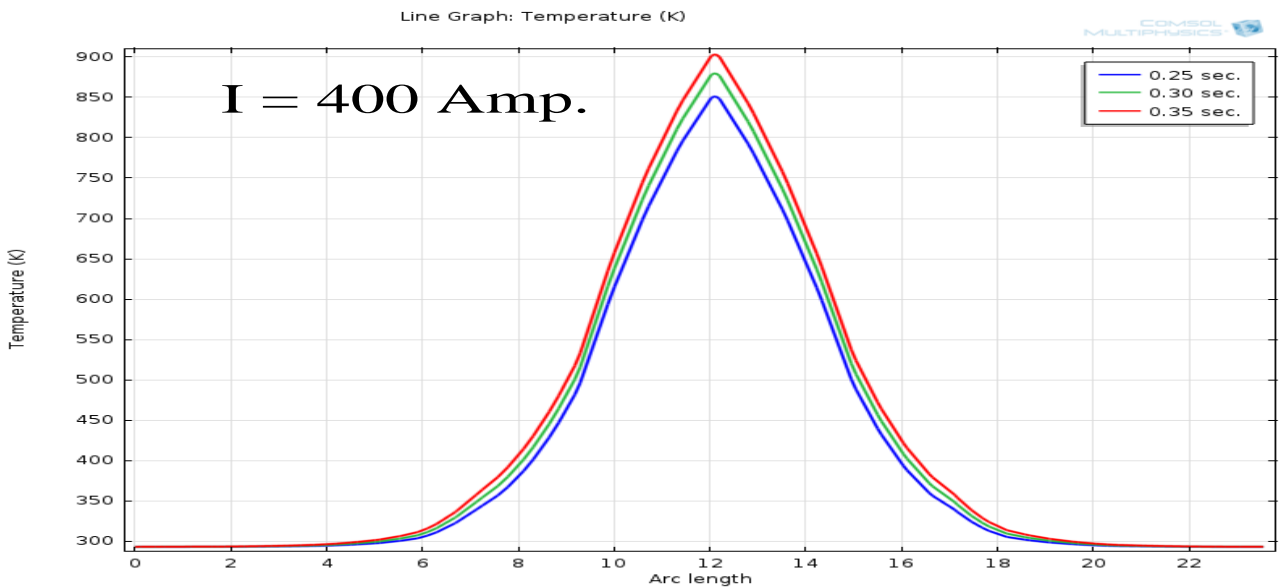

Fig. 13. Variation of temperature during time: $\mathrm{I}=400$ Amp. 


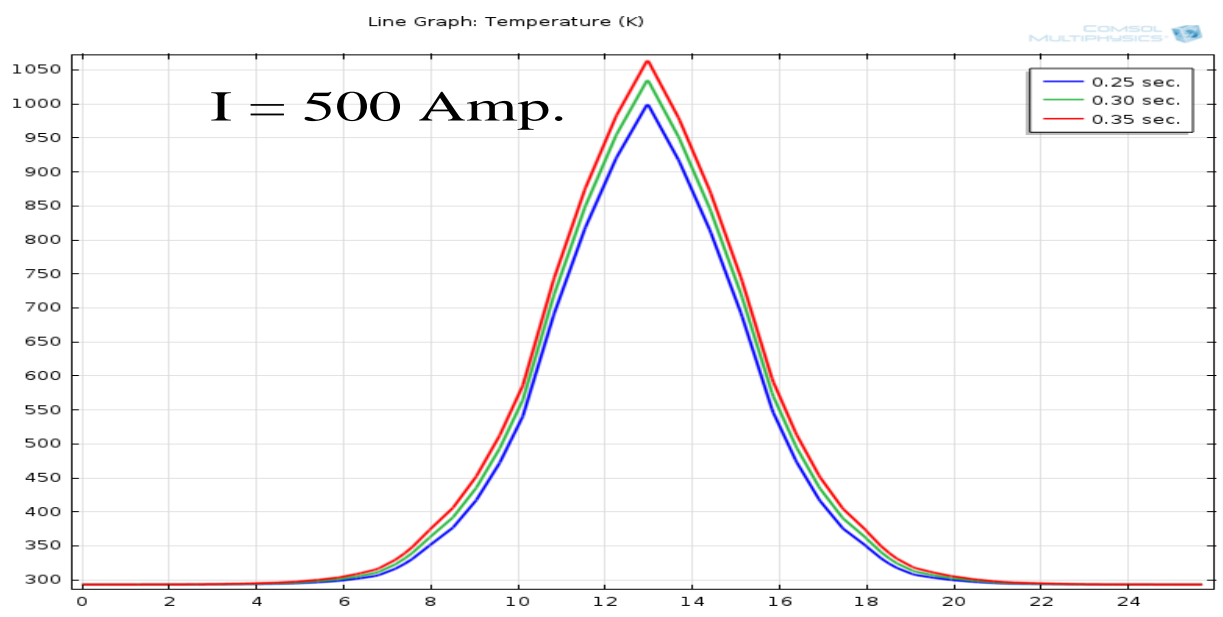

Fig. 14. Variation of temperature during time: $\mathrm{I}=500$ Amp.

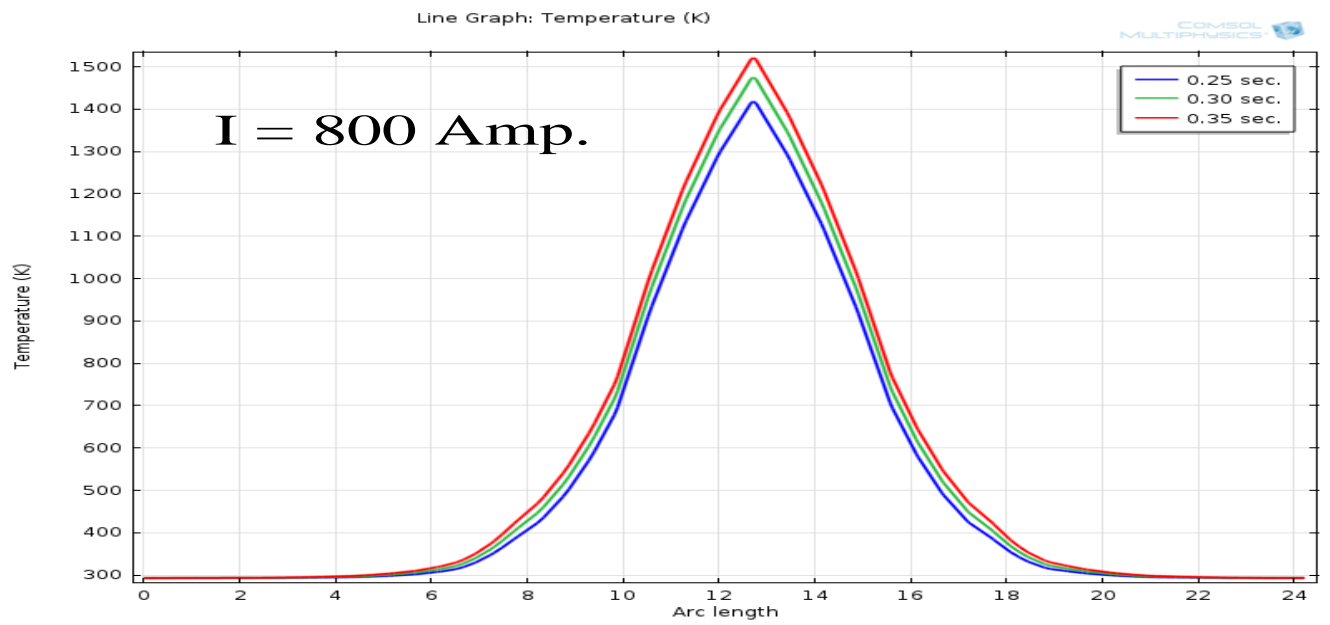

Fig. 15. Variation of temperature during time: $\mathrm{I}=800 \mathrm{Amp}$.

The computed individual desirability for each quantity characteristics using Eq. (7) is shown in Table 3. Equal weightage was given to all responses $(\mathrm{w} 1=\mathrm{w} 2=1 / 2$ and $\mathrm{w}=0.5)$. These values are considered for optimizing the multi response parameter design problem.

Table 3. Individual of composite desirability.

\begin{tabular}{|c|c|c|c|c|c|c|c|}
\hline $\begin{array}{l}\text { Torque } \\
\text { (N.m) }\end{array}$ & $\begin{array}{c}\text { Total } \\
\text { energy } \\
\text { flux } \\
\left(\mathrm{W} / \mathrm{m}^{2}\right) 10^{7}\end{array}$ & $\begin{array}{l}\text { Normalized } \\
\text { values of } \\
\text { torque } \\
\text { (N.m) }\end{array}$ & $\begin{array}{c}\text { Normalized } \\
\text { values of } \\
\text { total energy } \\
\text { flux } \\
\left(\mathrm{W} / \mathrm{m}^{2}\right) * 10^{7}\end{array}$ & $\begin{array}{c}\text { Weighted } \\
\text { desirability } \\
\text { of torque } \\
\text { (N.m) }\end{array}$ & $\begin{array}{c}\text { Weighted } \\
\text { desirability } \\
\text { of energy } \\
\text { flux }\end{array}$ & $\begin{array}{l}\text { Composite } \\
\text { desirability }\end{array}$ & Rank \\
\hline 16 & 1.7127 & $\overline{0}$ & 0 . & $\overline{0}$ & $\overline{0}$ & 0 & 9 \\
\hline 17 & 1.7153 & 0.025773196 & 0.001511013 & 0.160540325 & 0.03887175 & 0.07899673 & 8 \\
\hline 21.8 & 1.7166 & 0.149484536 & 0.002266519 & 0.386632301 & 0.047607977 & 0.135671594 & 7 \\
\hline 23 & 2.1413 & 0.180412371 & 0.249084675 & 0.424749775 & 0.499083835 & 0.460419099 & 6 \\
\hline 41.8 & 2.1443 & 0.664948454 & 0.250828151 & 0.815443716 & 0.500827467 & 0.63905916 & 5 \\
\hline 54.8 & 2.1459 & 1 & 0.251758005 & 1 & 0.501754926 & 0.708346614 & 4 \\
\hline 38.6 & 3.426 & 0.582474227 & 0.995699425 & 0.76399991 & 0.997847395 & 0.872672403 & 3 \\
\hline 49.9 & 3.4309 & 0.87371134 & 0.998547103 & 0.934725275 & 0.999273287 & 0.966460552 & 1 \\
\hline 40.5 & 3.4334 & 0.631443299 & 1 & 0.794634066 & 1 & 0.891422496 & 2 \\
\hline
\end{tabular}


The effect of different stud welding parameters on torque and heat transfer can be studied by using response graph and response table. The mean response values for each level of parameter on composite desirability were calculated and presented in table 3 and graphically shown in Fig. 16. Basically, the larger the composite desirability, the better is the multiple performance objectives of maximum torque and maximum heat, i.e. the maximization of composite desirability value in Fig. 16. The optimal parameter condition was obtained as:

- Current (amp) level (3).

- Time (sec) level (3).

- $\mathrm{X}(\mathrm{mm})$ level (3).

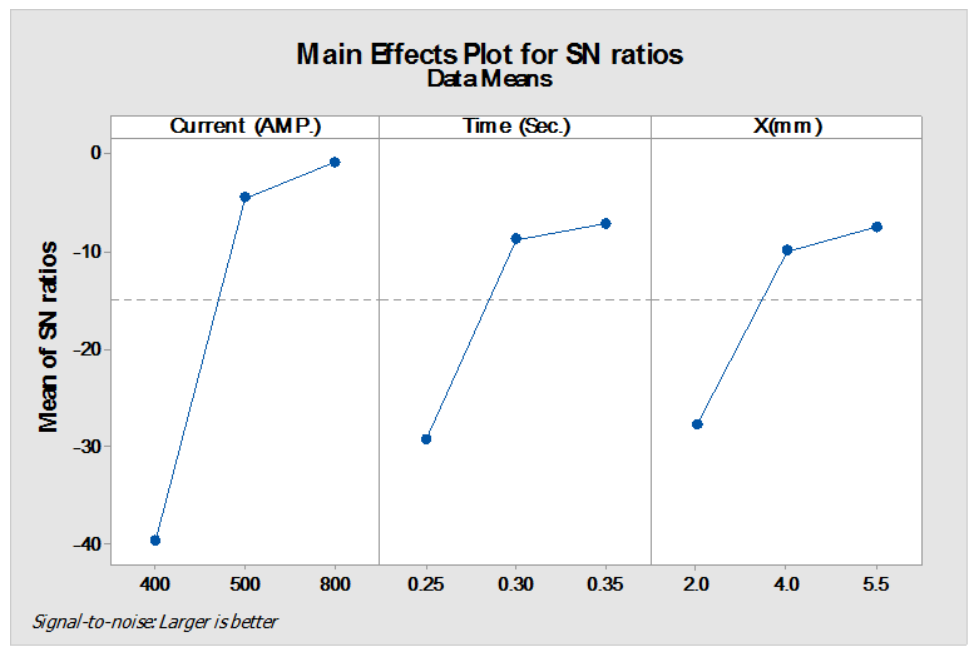

Fig. 16. SN plot of composite desirability.

The highest torsion resistance was observed in the specimen 6 , therefore the microstructure of this specimen was considered to explain the metallurgy of the welded section, as shown in Fig. 17. Generally, the section is classified into the following regions; nugget zone (NZ), thermo-mechanical affected zone (TMAZ), heat affected zone (HAZ) and base material (BM). In the NZ shown in Fig. 17(a), the highest plastic deformation and peak value of temperature occurred. This region contains the Martensite and ferrite. The fusion zone line appears clearly between the NZ and the TMAZ as in Figs. 17(b) and (c) [14]. The coarse grain size with higher dislocation was found in the TMAZ. The third region HAZ is followed directly by the TMAZ, in which, only thermal cycle without deformation or melting was occurred [14]. As a result, the microstructure was changed and fine grain size was found as shown in Figs. 17(c) and (d). A small region lies between the HAZ and the BM can be considered as a partially effected zone as shown in Figs. 17(d) and (e). The base metal was observed clearly which contains the ferrite and perlite as in Fig. $17(\mathrm{f})$. 

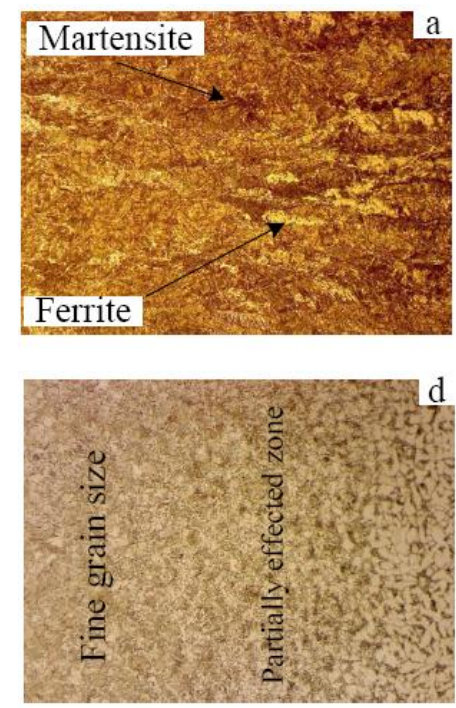
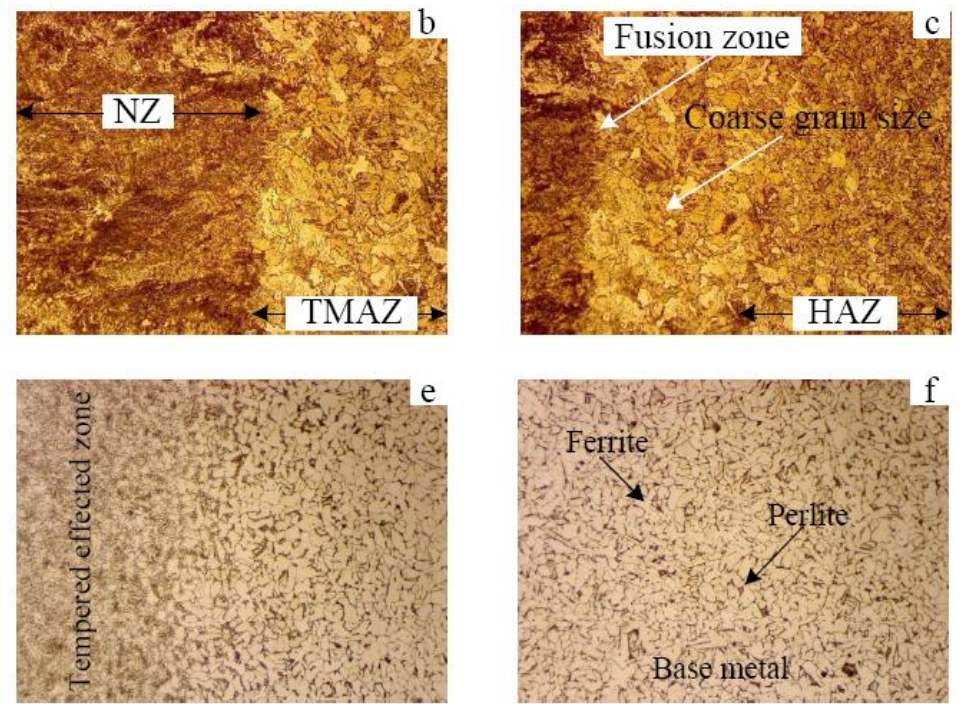

Fig. 17. Microstructure of stud welding specimen 6.

\section{Conclusions}

1- The heat input during stud welding has higher effect on the mechanical properties and welding quality.

2- Increasing the welding time at small applied current results in increasing the torsional resistance and model temperature.

3- Increasing the welding at $500 \mathrm{~A}$ current, gives a sufficient heat input to weld the stud with a torsional resistance more than those of stud.

4- At higher applied current of $800 \mathrm{~A}$, the plunge effect is clearly appeared, such that the torque value decrease with the increasing of the plunge.

5- The suggested FE model gave good agreement with the experiment.

6- The maximum symmetrical temperature is found at the center point of the model and decreases gradually away from this center.

7- The higher ranges of temperature are at the stud section as compared to the plate.

8- Higher ranges of temperature generated at higher current.

9 - The stud plunge has no effect on the temperature values.

\section{References}

[1] D. Dean, K. Shoichi, S. Hisashi, M. Hidekazu, and H. Yukihiko, "Numerical investigation on welding residual stress in $2.25 \mathrm{Cr}-1$ Mo steel pipes," Transactions of JWRI, vol. 36, pp. 73-90, 2007.

[2] KÖCO. (2013). Stud Welding-Technology. KÖSTER \& CO. [Online]. Available: www.bolzenschweisstechnik.de [Accessed: April 15, 2014].

[3] C. Hsu and J. Mumaw, "Wedability of advanced high-strength steel drawn arc stud welding," Welding Journal, vol. 90, pp. 45-53, 2011.

[4] GSI SLV and München, "Bewertung und optimierung der tragfähigkeit von gewindebolzenschweißenverbindungen unter ermüdungsbeanspruchung," Report in SLV München, 2011.

[5] S. K. Hussein and O. S. Barrak, "Analysis and optimization of resistance spot welding parameter of dissimilar metals mild steel and aluminum using design of experiment method," Eng. \& Tech. Journal, Part (A), vol. 33, no. 8, 2015.

[6] S. K. Hussein and O. S. Barrak, "Optimization the resistance spot welding parameters of austenitic stainless steel and aluminum alloy using design of experiment method," Eng. \& Tech. Journal, Part(A), vol. 34, no. 7, 2016.

[7] R. M. A. Hamza, "Optimized stud arc welding process control factors by Taguchi experimental design technique," in Welding Processes. Gulf University, Kingdom of Bahrain: Intech, 2012, ch. 15, pp. 369394. 
[8] S. K. Hussein, "Theoretical analysis, finite element method and optimization of heat generation in friction stir welding from different probe and shoulder profiles," International Journal of Advance Research, vol. 4, no. 5, May 2016.

[9] S. K. Hussein, "Analysis of the temperature distribution in friction stir welding of AA 2024-T3 and AA 6061-T6 using finite element method," U.P.B. Sci. Bull., Series D, vol. 78, no. 4, 2016.

[10] S. Kou, Welding Metallurgy. John Wiley \& Sons, Inc., 2003.

[11] J. P. Holman, Heat Transfer. McGraw-Hill Companies, Inc., 2010.

[12] J. Antony, Design of Experiments for Engineers and Scientists. Butterworth Heinemann, 2009.

[13] E. K. Zavadskas, A. Zakarevicius, and J. Antucheviciene, "Evaluation of ranking accuracy in multicriteria decisions," Informatica, vol. 17, no. 4, pp. 601-618, 2006.

[14] P. Dong, H. Li, and D. Sun, "Effect of welding speed on the microstructure and hardness in friction stir welding joints of 6005A-T6 aluminum alloy," Materials and Design, vol. 45, pp. 524-531, 2013. 